\title{
A crise do século XVII e a consolidação da eco- nomia-mundo (1600-1750)
}

José Jobson de Andrade Arruda

Departamento de História - FFLCH/USP

Em 1980, a Academic Press publicou o segundo volume da série The Modern World-System de Immanuel Wallerstein, originalmente prevista para cinco tomos. De acordo com esta programação - que aparece na introdução do texto publicado em 1974 (1) —, o segundo volume deveria cobrir o período de 1640 a 1815 , tendo por objeto o tema da consolidação do sistema mundial da Época Moderna. A temática permaneceu a mesma, porém a fatia cronológica foi estreitada, estancando no ano de 1750. O novo recorte cronológico parece-nos, inclusive, mais adequado, pois corresponde à fase II do tred mercantilista, consagrado na expressão de Gaston Imbert (2). Concomitantemente, recompõe mais corretamente a abrangência cronológica prevista para o terceiro volume, uma vez que

(1) - Veja nossa resenha crítica sobre o primeiro volume da obra de Immanuel Wallerstein, publicada na Revista de História (Nova Série), $\mathrm{n}^{\mathbf{9}} 115,1983$, pp. $159-166$.

(2) - A fase B do Tred Mercantilista desenrolou-se entre 1635-1650 e 1722-1743, a partir da análise de vários autores em diferentes países. Cf. Imbert, Gaston., Des mouvements de longue durée Kondratieff. Aix-en-Provence, 1959, p. 18 . 
para para a temática do industrialismo, especialmente na sua dinâmica tecnológica, a data de 1750 fica mais ajustada, pois praticamente coincide com a demarcação da Revolução Industrial a partir do ano de 1760 (3). Outra mudança significativa é a inclusão da expressão Mercantilismo, no subtítulo (4).

Neste aspecto particular, talvez valha a pena considerar que a leitura da obra revela uma questão fulcral: o problema das hegemonias e os consecutivos deslocamentos dos centros dinâmicos, reproduzindo, em larga medida, a estrutura do quarto capítulo do primeiro volume, De Sevilha a Amsterdam: o Fracasso do Império, bem como o sexto capítulo, $A P e$ riferia Frente à Arena Exterior. Em decorrência do conteúdo efetivo do texto, pensamos que seria mais apropriado intitulá-1o Economia Mercantil, expressão mais genérica e adequada do que Mercantilismo, cuja simples nomeação traz consigo uma conotação específica que o termo comporta e que, no fundo, não é alvo de estudo sistemático. Transforma-se, por isso mesmo, num rótulo vazio, procedimento impróprio para qualquer obra de peso, como é o caso deste estudo de Wallerstein.

A distribuição dos capítulos revela claramente a estrutura da obra no seu conjunto. Parte da caracterização ampla do grande século XVII (1640-1750), definido como uma fase de desaceleração, de retomada de fôlego da economia-mundo, prenúncio da exploração do século XVIII patenteada na Revolução Industrial. No contexto da fase B do tred mercantilista, Wallerstein destaca a hegemonia holandesa na economia-mundo; as lutas entre os países que formam no coração do sistema divididas em duas fases: 1651-1689 e 1689-1763. Entre ambas as fases, analisa a situação da periferia num momento de crescimento desacelerado e as mutações na semiperiferia.

A questão fundamental que perpassa todo o conjunto é a demarcação e a explicação da tão discutida "crise do século XVII", entendida como uma questão intelectual plena de significado uma vez que, segundo Wallerstein, nesses momentos pouco freqüentes os mecanismos de compensação dentro do sistema social comprovam-se insuficientes, à vista da multi-

(3) - Esta data foi consagrada por Ashton, T. S., The Industrial Revolution 1760-1830. Oxford University Press, 1960. Tomando por base o momento do arranque (take off), prefere-se a data de 1780, como se vê em Hoffmann "The growth of industrial production in Great Britain: a quantitative study", The Economic History Review; second series, vol. 2, n $\mathrm{n}^{\circ}$, 1949, pp. 162-180. Considerando-se a transformação vital que se opera no interior da sociedade inglesa, certamente poderiamos usar os limites entre 1780 e 1800 , os "anos revolucionários". Cf. Arruda, José J. de A., Revolução Industrial e Capitalismo. Brasiliense, São Paulo, 1984, p. 20.

(4) - O título completo do trabalho é The Modern World-system II. Mercantilism and the Consolidation of the European World-Economy, 1600-1750. New York, Academic Press, 1980. 
plicação dos atores sociais que uma reestruturação ampla da economia engendra, sem que isto signifique uma redistribuição simples de vantagens dentro do sistema.

No quadro dos pressupostos gerais definidos no primeiro volume, atinentes à dinâmica global do sistema-mundo, segundo os quais manifestase um padrão de expansão e contração cíclicas que transforma a alocação geográfica e o papel econômico das variadas regiões imbricadas no sistema - resultando na ascensão e queda das hegemonias, nos movimentos de alta e baixa de uma região central específica ou das zonas semiperiféricas e periféricas - o século XVII, cobrindo aproximadamente o período de 1600 a 1750 é, primacialmente, um exemplo de padrão cíclico de expansão e contração. A meta do autor é explicar por que este fenômeno cíclico ocorre, delinear suas repercussões em termos de formação de classes, as lutas políticas e as manifestações culturais embutidas na viragem econômica. A partir de uma descrição empírica, o que se pretende é a especificação da teoria geral do desenvolvimento capitalista como parte da teoria mais ampla das mudanças sócio-históricas.

A evidência empírica quantitativa é rarefeita neste período e, além do mais, parcial e esporádica. Com relação à análise das variáveis no nível da estrutura social, a situação é bem pior. O procedimento metodológico exige, pois, a análise dos dados dispersos, a esquematização daquilo que parece ser mais sólido, a revisão dos modelos explicativos e a integração dos dados, sugerindo uma revisão teórica. No limite, chegar a algumas noções a respeito das lacunas empíricas existentes. É nos parâmetros estabelecidos por estes pressupostos que Wallerstein pretende examinar a historiografia relativa à "crise", à "retração relativa" ou ao "crescimento desacelerado" do século XVII. Vislumbramos, portanto, alguns pressupostos da New Economic History, especialmente na "possível" reconstituição de dados escassos.

A análise da crise do século XVII, ou melhor, a sua constatação, processa-se com base em seis indicadores conjunturais estratégicos: a contração e a expansão agrícolas, a perda de aceleração industrial; a redução dos preços, apresentando em contrapartida a elevação relativa dos salários, apesar da contração na oferta de empregos; o encolhimento do estoque monetário e do sistema de crédito; a estabilização das relações comerciais intercontinentais, por oposição ao flagrante expansionismo do século XVI; o leve declínio ou o pequeno ganho em termos populacionais. Repassando alguns desses itens, Wallerstein conclui que pelo menos em quatro setores constatava-se uma certa expansividade: na população ecoplada ao suprimento de alimentos, na indústria urbana alicerçando ganhos reais de salário, no estoque monetário na forma de bulhão, papel-moeda e crédito, bem como na ampliação do número de entrepreneurs rurais e urbanos. 
Para explicar estruturalmente a crise do século XVII, remonta-se à explicação social da crise do feudalismo, a partir das explicações de Dobb e Kosminsky (a superexploração realizada pela camada dominante sobre os servos) e as contestações de Perry Anderson (que combina a tese da exploração com a exaustão econômica do sistema). Wallerstein propõe uma terceira linha explicativa, argumentando que a crise sócioeconômica enfraqueceu a nobreza na mesma proporção em que os camponeses incrementaram firmemente a sua participação no excedente, entre 1250 e 1450-1500. Nestes termos, verificar-se-ia uma elevação real do padrão de vida, empurrando no sentido de uma equalização dos rendimentos, muito mais do que a exaustão do sistema que, para a camada dominante, representaria a crise real e o dilema a ser enfrentado.

Analisar o período de 1450 a 1750 como uma "longa transição" do feudalismo ao capitalismo, correria o risco de reificar o conceito de transição pela redução do feudalismo anterior e do capitalismo posterior a entidades "puras", o que contrariaria o pressuposto fundamental de que "a mistura é a essência do modo capitalista de produção" (5). A dimensão política da transição, a questão do Estado Absolutista, da forma pela qual foi colocada por Perry Anderson, para quem o "absolutismo foi, essencialmente, uma reordenação do aparato de dominação feudal destinado a manter a massa camponesa na sua posição tradicional - a despeito e contrariamente aos ganhos que tinham realizado pela generalização da comutação das obrigações" (6), é plenamente assumida por Wallerstein, desde que se faça a substituição do adjetivo feudal por capitalista. Equivale dizer que a interpretação de Anderson, segundo a qual persiste uma variedade de modos de produção sob a hegemonia do modo de produção feudal declinante, é substituída pelo modo de produção capitalista ascendente, modo de produção este cujos fundamentos concretos não chega nunca a formular claramente.

A discussão desses pressupostos estruturais, seja da natureza social ou política da transição, fica descolada da análise da crise do século XVII, pois "a contração do século XVII não foi uma crise do sistema. Muito pelo contrário, foi um período de consolidação (...) Política e culturalmente, o século XVII representou uma busca de estabilidade na forma e na estrutura concomitantemente com o momento de desaceleração na taxa de desenvolvimento da economia-mundo (...) Isto faz do século XVII não um momento de crise, mas de mudança necessária de ritmo, não um desastre, mas um elemneto essencial na postergação

(5) - Idem, ibidem, p. 32. 1974, p. $\overline{18}$.

6) Anderson, Perry., Lineages of the Absolutist State, Verso, London, 
dos interesses daqueles que mais se beneficiavam do sistema capitalista" (7).

Ficamos com a impressão de que a análise da crise do século XVII fica mais no nível da constatação, uma vez que o aprofundamento do tema imporia, não apenas a reprodução das interpretações antagônicas e precedentes, mas a sua discussão. Pensamos, especificamente, na hipótese explicativa de Eric Hobsbawm, a quem coube a abertura do debate sobre esse tema na revista Past \& Present e que mereceu, por esta mesma razão, uma edição especial conjuntamente com outros artigos a respeito do mesmo tema do editor Trevor Aston (8). A explicação de Hobsbawm para a crise geral do século XVII, cremos, no estado atual da questão, é imbatível. O overlapping entre dois modos de produção antagônicos nas suas linhas essenciais - o feudalismo preponderante na maior parte da sociedade rural européia e o capital mercantil emergente nos centros urbanos - constitui-se no corpus privilegiado da questão. Nem mesmo a vertente explicativa de Lublinskaya (9), segundo a qual o cerne da crise jazia no lento desenvolvimento do capitalismo nessa fase, uma propriedade inerente à própria manufatura e não aos entraves impostos pelo meio feudal circulante - que poderia ser utilizada para contestar a explicação de Hobsbawm - foi aventada. A lateralização dessas questões, a nosso ver essenciais, remete a crise do século XVII para o nível das explicações conjunturais, dada a sua descaracterização: $1^{\circ}$.) como crise em si; $2^{\circ}$.) como fruto de um descompasso estrutural.

Tendo por pano de fundo a "descaracterização" da crise do século XVII, Wallerstein passa a delinear o coração da economia-mundo por volta de 1600, firmemente estabelecido na região nordeste da Europa: na Holanda e Zelândia; em Londres, nos Home Counties; e na região ocidental e nordeste da França. O poderio econômico da Holanda assentava-se no desenvolvimento da indústria têxtil. construção naval, refinarias de açúcar e uma variedade significativa de outras indústrias, cuja estrutura doméstica de produção, assentada nas guildas artesanais de origem medieval, transformava-se no sentido das manufaturas e do puttingout system. A frota holandesa dominava o comércio carreteiro no século XVI. Crescera dez vezes entre 1500 e 1700 . Por volta de 1670 possuia três vezes mais tonelagem do que a frota inglesa e mais tonelagem do que a Inglaterra, França, Portugal, Espanha e Países Germânicos conju-

(7) - Wallerstein, Immanuel., obra citada, pp. 33-34.

(8) - Aston, Trevor. (org.), Crisis in Europe 1560-1660. Routledge, London, 1965 , passim.

(9) - Cf. Lublinskaya, A. D., La Crisis del Siglo XVII y la Sociedad del Absolutismo. Trad. esp., Editorial Crítica, Barcelona, 1979, p. 87. 
gados (10). Certamente a atividade econômica dos holandeses muito contribuiu para o desenvolvimento da economia-mundo. Mas teria a Holanda recebido os mesmos benefícios? Charles Wilson responde que não (11), pois, apesar de ser um dos Estados mais modernos da Europa, com enorme disponibilidade de capital, baixas taxas de juros e salários elevados, seus capitais foram orientados para o financiamento do comércio exterior, dos empréstimos internacionais, sem passar decididamente ao setor produtivo da economia, onde se manifestava uma verdadeira hostilidade entre o capital mercantil e o capital industrial. Tratava-se, efetivamente, de um fenômeno de cristalização mercantil (12).

O tema das hegemonias leva Wallerstein ao estabelecimento de uma diferenciação - que ele mesmo reconhece arbitrária e confusa - entre clivagem intraestado e interestado. Os períodos de ascensão hegemônica favorecem a primeira forma, que leva à luta pela conquista de mercados. $\mathrm{Na}$ fase descendente da hegemonia, abre-se espaço para as lutas políticas entre as facções sociais dentro dos Estados.

Nos meados do século XVII delineava-se, claramente a nova atitude franco-inglesa em relação aos holandeses. Procuravam definir seus próprios interesses, eliminando-os antes de se enfrentarem numa etapa ulterior. Mesmo porque, na ausência de um poder militar efetivo, os países semiperiféricos tais como a Prússia, Suécia e Áustria procuravam ampliar suas vantagens. Em 1763, a supremacia inglesa sobre a França e a Holanda ficava claramente estabelecida; no mesmo ano, o êxito da Prússia no jogo de forças entre as nações semiperiféricas estava definido e prenunciava o curso futuro das tendências políticas centro-européias. A contração e a reorganização das áreas periféricas foi completa, criando condições para o avanço geográfico da economia-mundo.

Os Atos de Navegação de 1651 foram disparados, sobretudo, contra a hegemonia holandesa (13). O papel do Estado neste particular foi decisivo. A propósito, Wallerstein diz: "Eu vejo a história moderna do Estado como uma longa busca da criação de estruturas suficientemente fortes para defender os interesses de um grupo de proprietários-produtores na economia-mundo, contra outros grupos proprietários-produtores, tanto quanto. obviamente, contra os trabalhadores" (14). A supremacia

(10) - Wallerstein, Immanuel., obra citada, p. 46.

(11) - Cf. Wilson, C., Anglo-Dutch Commerce and Finance in the Eighteenth Century, Cambridge University Press, 1941, pp. 199 e segs.

(12) - Cf. Mokyr, Joel., "The Industrial Revolution in the Low Countries in the First Half of the Nineteenth Century: a Comparative Case Study". Journal of Economic History, vol. 34, no 9, 1974, pp. 365-391.

(13) - Wallerstein, Immanuel., obra citada, p. 76.

(14) - Idem, ibidem, p. 114. 
inglesa na construção deste aparelho de Estado, que preenchesse essas funcões, repousava nas tronsformações decorrentes da Revolução Inglesa de 1640. Não acompanhamos plenamente as considerações de Wanerustem a respeito do sentido social dessa Revolução. Para ele, a grande diferença entre 1640 e 1660 , se dá, sobretudo, em termaos sociais e não políticos. Considera que a polarização entre nobreza e burguesia é uma idéia histórica, porquanto estes grupos sociais não eram radicalmente diferentes. "As lutas políticas e sociais eram reais, mas eram internas à camada dirigente" (15). A expansão econômica do século XVI criou condições para a emergência da burguesia como classe social e seu relacionamento com o grupo social dominante era nebuloso. Não foi necessário clarificar esta situação enquanto o ritmo da expansão econômica permaneceu elevado. Porém, tão logo vislumbraram-se os limites da expansão econômica, a luta para definir o controle da máquina do Estado tornou-se aguda. Contudo, as contínuas dificuldades econômicas impuseram um compromisso de facto entre as duas facções, na medida em que a luta política resvalou do seu controle para as camadas mais baixas, urbanas e rurais, que firmaram suas posições de forma vigorosa, independente e direta. No fundo, "o triunfo da aristocracia proprietária foi, de fato. o triunfo das classes capitalistas" (16).

A simples identificação dos interesses burgueses e aristocráticos, confluentes na produção mercantil destinada ao mescado capitalista, não uniformiza estes dois segmentos sociais a ponto de fundi-los numa única classe. descaracterizando totalmente a luta de classes e o caráter burguês da Revolução. Afinal, esta Revolução se define como burguesa, muito menos pela genealogia social de seus figurantes e muito mais pelo que ela criou, isto é, condições plenas para a conquista dos mercados mundiais e a realização das transformações vitais na estrutura agrária via cercamentos, as quais desataram o nó das contradições que, estruturalmente. engendraram a crise do século XVII, disparando as forças produtivas capitalistas que eclodiram na Revolução Industrial. O raciocínio de Wallerstein segue de perto o perfil da one class society de Laslett (17), posição esta, que a nosso ver, obscurece o processo de mudança social mais dinâmico e conseqüente.

Das lutas hegemônicas que se desenrolam entre os Estados e no interior dos Estados situados no centro do sistema, Wallerstein passa à caracterização das áreas periféricas numa fase de crescimento menos acelerado. Por constituir-se na parcela politicamente mais frágil do conjunto da economia-mundo, seria de se esperar que os grupos dirigentes no centro e na semiperiferia procurassem preservar o nível de produção e em-

(15) - Idem, ibidem, p. 120.

(16) - Idem, ibidem, p. 123.

(17) - Laslett, P., The World We Have Lost. Methuen, London, 1965. 
prego às expensas das áreas periféricas. A regressão lhes impõe tanto a involução quanto a evolução; tanto uma significativa contração na parcela monetarizada da economia quanto a emergência de novos empreendimentos econômicos; tanto o abandono ou reestruturação quanto a realocação de recursos; tanto o declínio quanto o aprofundamento e ampliação da especialização na economia-mundo. Um conjunto aparentemente paradoxal, mas que reproduz a dinâmica do capital mercantil. Discorrendo e analisando a economia açucareira, a economia da mineração, o autor centra sua atenção nas formas de trabalho imperantes, especialmente com relação à tendência, nada casual, de a substituição do trabalho escravo coincidir regularmente com os períodos de boom econômico. Reversamente, nos momentos depressivos intensificava-se a utilização do "trabalho forçado em cultivo para o mercado" (coerced cashcrop labour), pois os custos recorrentes do trabalho escravo eram mais elevados. Nas regiões expandidas do Caribe - a nova periferia entre 1600 e 1750 - o trabalho escravo organizado era a forma básica da produção "proletária" (18), mais do que o trabalho assalariado, arrendatário ou coerced cash-crop labour.

Entre as lutas hegemônicas da primeira fase do século XVII, verificadas no centro da economia-mundo, e a situação da periferia numa fase de crescimento desacelerado, a semiperiferia encontrava-se numa verdadeira encruzilhada, afetando diretamente a preponderância política do Estado. No século XVII, muitas áreas semiperiféricas perderam terreno, a exemplo da Espanha, Portugal e a velha espinha dorsal européia (da Flandres, através da Alemanha até o norte da Itália). Havia, porém, algumas poucas áreas privilegiadas que conseguiam avançar: notadamente a Suécia, o Brandemburgo-Prússia e as Colônias Inglesas da América do Norte e Central, sobretudo a Nova Inglaterra (19). Um tratamento diferenciado é dado a Portugal pelo autor, especialmente aos debates entre os historiadores centrados na crise comercial do século XVII e a política industrialista do conde da Ericeira. Também ganha relevo a análise dos tratados ingleses que culminaram no Tratado de Methuen e seu impacto sobre Portugal, particularmente na questão nevrálgica do bloqueio à industrialização. Da mesma forma, estuda-se com proficuidade o papel do ouro brasileiro no equilíbrio da balança comercial portuguesa em relação à Inglaterra, fundamental para a preservação da condição semiperiférica de Portugal que, outrossim, resvalaria para a condição de periferia do sistema.

(18) - Assumir a forma escrava de produção como forma "proletária" soa, no mínimo, estranho. Cf. Wallerstein, Immanuel, obra citada, p. 175 .

(19) - Idem, ibidem, p. 179. 
Resumindo, o período de 1600 a 1750 foi dominado pelos esforços ingleses e franceses para deslocar a hegemonia holandesa em favor de si próprios. Nesse longo período de relativa estagnação - comparativamente ao desempenho econômico durante o século XVI - as áreas periféricas sofreram uma exploração exacerbada, diminuindo consideravelmente as vantagens das camadas dominantes autóctones (comparativamente, é claro, aos ganhos realizados pelas camadas dominantes no centro do sistema). A história da semiperiferia foi mais complexa. Os países centrais procuraram transformá-la em intermediária na extração de valor originária da periferia. Tiveram êxito. Porém, numa época de intensa rivalidade no centro, algumas zonas semiperiféricas conseguiram incrementar suas posições - caso da Suécia, da Prússia e, em menor escala, das colônias da Nova Inglaterra (20).

No último capítulo do livro, o autor retoma a questáo da luta pela hegemonia no centro do sistema, agora na sua II fase, de 1689 a 1763, figurativamente chamada de Segunda Guerra dos Cem Anos, marcada pela intensa rivalidade anglo-francesa, praticamente sem tréguas, que terminou com a vitória inglesa ao findar da Guerra dos Sete Anos em 1763. Com descernimento, Wallerstein analisa as razões do êxito dos empreendimentos ingleses, remetidos à agressividade do Estado fundado, segundo ele, na relação social de compromisso nobreza-burguesia. A comparação entre a Inglaterra e outros Estados centrais, especialmente a França, revela uma notável semelhança nas suas estruturas básicas. $\mathrm{O}$ denominador comum desse período é atribuído à sua coloração social, isto é, à idéia de que os grupos sociais tendiam a agir, precipuamente, como burgueses ou proletários, buscando a defesa de seus interesses e defendendo seu quinhão na arena do sistema capitalista. "Este é, verdadeiramente, o núcleo da minha argumentação. Nem a cultura burguesa nem a proletária tinham ainda emergido; mas, a praxis burguesa e proletária já formavam a coação central do sistema social" (21).

A guisa de conclusões, poder-se-ia dizer que as críticas metodológicas apontadas na resenha do primeiro volume podem ser reproduzidas para este texto, ainda mais que em certos passos da análise podem ser detectadas de modo flagrante. Tal é o caso do sistemático e recorrente deslocamento da precedência econômica entre as regiões do polo central da economia-mundo, as regióes semiperiféricas e periféricas que revela, no fundo, uma sofisticação mais apurada da teoria de centro e periferia, num contexto marcado pela abordagem funcionalista de equilíbrios $e$ desequilíbrios.

(20) - Idem, ibidem, p. 241.

(21) - Idem, ibidem, p. 289. 
Contudo, se nossas indisposições em relação ao texto, particularmente no que tange à caracterização e explicação da crise do século XVII, à definição da natureza da Revolução Inglesa de 1640 - temas polares nesse segundo volume -, são insuperáveis, permanece o conceito assumido na resenha crítica do primeiro volume, oportunidade na qual consideramos o texto fundamental e digno de figurar na estante de qualquer estudioso ou especialista da Época Moderna. Quanto mais não fosse, seriam dignos de encômios, repitamos, os excelentes resumos realizados pelo autor a propósito das posições confrontantes de vários autores na discussão de temas cruciais do período, revelando conhecimento notável da bibliografia e que perfazem um repertório de real valor, mesmo que possamos discordar de algumas de suas interpretações ao penetrar nessas questões controvertidas. Exemplos fortes são: a transição e a natureza do Estado absolutista. Mas não podemos, in limine, negar o brilho de suas arquitetaçōes alternativas. 